PAPER

\title{
Medical ethics and more: ideal theories, non-ideal theories and conscientious objection
}

\author{
Florencia Luna
}

\section{Correspondence to} Dr Florencia Luna, Bioethics Program, FLACSO-Argentina CONICET, Ayacucho 555, Caba C1026AAC, Argentina; florlunaflacso@gmail.com

Received 29 August 2014 Revised 7 October 2014 Accepted 8 October 2014
CrossMark

To cite: Luna F. J Med Ethics 2015;41:129-133.

\begin{abstract}
Doing 'good medical ethics' requires acknowledgment that it is often practised in non-ideal circumstances! In this article I present the distinction between ideal theory (IT) and non-ideal theory (NIT). I show how IT may not be the best solution to tackle problems in non-ideal contexts. I sketch a NIT framework as a useful tool for bioethics and medical ethics and explain how NITs can contribute to policy design in non-ideal circumstances. Different NITs can coexist and be evaluated vis-à-vis the IT. Additionally, I address what an individual doctor ought to do in this non-ideal context with the view that knowledge of NITs can facilitate the decision-making process. NITs help conceptualise problems faced in the context of non-compliance and scarcity in a better and more realistic way. Deciding which policy is optimal in such contexts may influence physicians' decisions regarding their patients. Thus, this analysis-usually identified only with policy making - may also be relevant to medical ethics. Finally, I recognise that this is merely a first step in an unexplored but fundamental theoretical area and that more work needs to be done.
\end{abstract}

\section{INTRODUCTION}

This issue of the Journal of Medical Ethics marks the commemoration of an anniversary and celebrates bioethics and its evolution. It has been 40 years since this discipline began to shape its academic and current form. This young and flexible field has evolved and incorporated new theories into its classic ethical analyses. ${ }^{1}$ Nonetheless, 'new' theoretical tools still exist for consideration. Non-ideal theories (NITs), undertheorised and neglected, could be extremely germane to bioethics and medical ethics and should be further examined and refined.

In this article I will explore some theoretical analyses that are timidly appearing in bioethics: ideal and non-ideal theories. ${ }^{2}{ }^{\mathrm{i}}$ Rawls refers to an ideal theory (IT) as a well-ordered institutional arrangement. ${ }^{3}$ ii Institutions are well ordered when they are just and known to be just, and when individuals accept and fully comply with the requirements these institutions impose on them. ${ }^{4}$ This suggests at least two rather different ways in which circumstances may fail to be ideal. On the one hand, individuals may not fully comply; on the other, background institutions may not be just. I will

${ }^{\mathrm{i}}$ For example, in research ethics. ${ }^{2}$

ii The details of Rawls' interpretation go beyond this article. $^{3}$ introduce a corresponding branch of NIT for each kind of defective case and explore its possibilities. ${ }^{5-7}$ iii

First, I will show how NITs can contribute to policy design in non-ideal circumstances and can be pertinent to bioethics. Second, I will indicate how in non-ideal contexts knowledge of NITs may help an individual doctor in her moral decision-making process. Thus, this knowledge-usually identified only with policy making-may also be relevant to medical ethics. I will examine these issues with an example.

\section{CONSCIENTIOUS OBJECTION, IDEAL AND NOT SO IDEAL}

Isolating medical ethics from other analyses in bioethics is far from straightforward. A central theme in medical ethics is the patient-physician relationship. It would appear to be a specific and demarcated topic. Determining how to act could be based on ethical theory considerations. However, patientphysician relationships are not always simple, and can quickly become complex (eg, the request for an abortion). Existing public policies and context can play a decisive role. But when public policies do not exist-as in the case of conscientious objection (CO) in Argentina and many other Latin-American countries-physicians may have to confront dilemmas in a private sphere and question what their actions should be. In these 'indeterminate situations' (no rule to follow) theoretical issues arise and physicians should be prepared. A mindful physician may ask herself whether it is ethically justifiable to be an objector and how she can ethically implement her beliefs-if it is acceptable to object when she is a civil servant and works in the public system or if it matters whether she works in a private hospital. She may wonder whether she should speak to the hospital director and explain the situation. She may ask herself if she should just tell the patient that she refuses to perform the service or simply refer the patient to another colleague. Yet again, she may weigh her choices if she cannot refer the patient to another physician.

Let us pose the case of a woman who asks for a legally permissible abortion ${ }^{\text {iv }}$ following a rape. Argentina's laws approve abortion in only few cases: when the woman's health or life is at risk or

iii I am following Sreenivasan who argues for this distinction. ${ }^{5}$ Other philosophers, such as Murphy or Feinberg, only consider partial compliance. ${ }^{67}$

${ }^{\text {iv }}$ The Penal Code forbids abortions, but accepts some exceptions, deemed 'permissible abortions' that should be provided by the State. 
when the woman has been raped. The physician does not want to perform an abortion due to her CO. At first sight the answer seems straightforward: the physician objects and a non-objector physician performs the abortion. All interests and rights are respected and protected: those of the woman and those of the physician involved. A scheme of an $\mathrm{IT}^{\mathrm{v}}$ on $\mathrm{CO}$ involves, at least, two main prescriptions: 1 . Permissible abortions should be provided; 2 . CO should be accepted.

This is the ideal solution but I argue that it pertains to an 'ideal' world. ${ }^{\mathrm{vi}}$ Argentina, like most Latin-American countries, does not provide minimum sexual and reproductive (SS\&RR) healthcare. There is a long record of denial of and disrespect for SS\&RR rights, thus hindering permissible and safe abortions. Note that abortions have traditionally been carried out illegally with the accompanying harm and costs that women bear. So, a well-functioning infrastructure dealing with these cases does not exist (some hospitals do function well and provide the service but they are the exception to the rule). Few physicians working in the public system are willing to perform the service (out of fear of a judicial trial, discrimination or simply a lack of knowledge). Also, when permissible abortions are requested, the hospital staff frequently interferes, asking for unnecessary judicial orders to confirm the permissibility of the abortion, or requiring an ethics committee to analyse the case and approve the practice (common tactics to delay and prevent access).

In recent years it has become clearer ${ }^{\mathrm{vii}}$ that permissible abortions should be provided by the public system but, at the same time, the practice of $\mathrm{CO}$ has been thoroughly abused. In addition to $\mathrm{CO}$, gynaecology services 'express' institutional objections (IO). That is, they allege $\mathrm{CO}$ and refuse to perform any legal abortion. In general, this position is 'imposed' by the chief of gynaecology and subordinates must adjust to these views. Consequently, it is quite complex to find non-objectors who are willing to carry out permissible abortions.

The IT of $\mathrm{CO}$ assumes that reproductive rights are respected (at least those permissible by law), that services are accessible, and that $\mathrm{CO}$ is an exception; but let me simply assert that those assumptions do not hold in Argentina; SS\&RR rights are widely ignored, and $\mathrm{CO}$ and $\mathrm{IO}$ are common, not exceptional. However, if the IT is followed and the conscientious objector's choice is respected, we may anticipate an even greater lack of resources as yet more doctors and especially their institutions object, with a consequent reinforcement of an already unjust system. Even more poor women-already at risk or facing the terrible situation of pregnancy due to rape-with no chance of undergoing safe abortions will have to turn to unsafe illegal abortions with their increased risks of harm or even death, thus victimising the victim again. The attempt to impose perfect justice's rules is likely to backfire, making the worst off even worse off. Hence, it does not follow that we can simply apply the IT. ${ }^{8}$

The previous argumentation impacts our objector's deliberations. She is an ethical and mindful person. She does not want to uphold an abusive position. She knows she has special responsibilities for her patients' health. She accepts that some forms of CO may harm women (mainly when this implies a

\footnotetext{
'For an explanation of IT, see 'The non- ideal approach'. I will consider here the practice of $\mathrm{CO}$ as part of a broader theory concerning principles and obligations of agents.

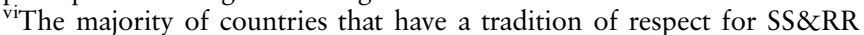
rights and provide those services can be considered to be in this category including most European countries.

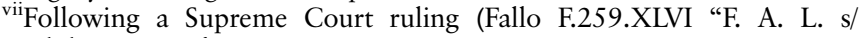
medida autosatisfactiva).
}

delay, or when the service is not provided-which as mentioned above is quite common). She is not against the practice if provided by others. She understands these abortions are exceptional and even "humanitarian" in the contexts of rape or risk to the woman's life or health. But she does not want to perform an abortion herself because of her religious convictions. Given this situation, and in an effort to decide what to do, the mindful objector finds three different candidate-positions regarding the permissibility and regulation of $\mathrm{CO}$.

\section{Three alternatives...not a clear answer}

The three candidate-positions concur on their main ethical analysis and are proposed by different groups in Argentina. The common denominator of these proposals is that $\mathrm{CO}$ regarding SS\&RR rights can harm third persons. It does not respect women's autonomy and violates their legal rights when the service is not provided. Moreover, the current practice of $\mathrm{CO}$ increases the unjust situation of women and creates yet another layer of vulnerability whereby their only resources are illegal and unsafe abortions.

The first position is usually defended by people in underpopulated regions with some tradition of respect for SS\&RR rights. However, they currently have to deal with a conservative Ministry of Health. Let us call their position the silent referral. They argue for an institutional and silent policy. CO should be reported only to the director of the healthcare institution without constraints. IO is accepted. The only requirement is that the director should have a plan for dealing with the situation. ${ }^{\text {viii }}$ For example, if everyone objects (these may be small hospitals), the director should have an agreement with a nearby institution (perhaps $200 \mathrm{~km}$ away or more) that can perform the abortion and an ambulance at hand for the patient. Only the director has to know who the objector is in order to have a plan. There should be no public registry or transparency because that might trigger a paradoxical effect. They argue that, on the one hand, people that do not object will be stigmatised; on the other, if this becomes public and transparent, it will generate a strong reaction from conservative groups. A more aggressive policy, they add, will generate a negative effect and the still powerful conservative groups will hinder what has already been gained silently.

The second position is the careful ruler proposal. ${ }^{9}$ Neither silent referral nor institutional registry nor IO is accepted. They would admit the referral system mainly as a concession to existing conditions, as a compromise position, if and only if there is true access to SS\&RR rights. They argue that physicians have the monopoly over certain practices and their decision to become physicians is voluntary. They have a privileged role; hence, society should set rules and limits on their CO. They ask for proper regulation: (1) 'quotas' (50\% or less of CO) so as to be able to provide the service and avoid the stigmatisation or overburdening of the non-objectors; (2) public CO registries (to prevent double standards whereby doctors refuse to perform free abortions at a public hospital but do so privately, charging fees (Argentine physicians generally work at public hospitals in the mornings and at their private offices in the afternoons)). Publicity and transparency will inform women who to contact; (3) an evaluation of who a 'true' objector is via interviews. The objectors will have to renew their CO periodically and restate their belief.

\footnotetext{
viii Personal communication with the group leader.
} 
Let us call the third candidate the temporary probibition. ${ }^{10}$ This position considers the situation of very conservative regions with no respect for SS\&RR rights, where IO prevails throughout the region. It takes into account the context, the existing unfairness, the lack of rules and unwillingness to modify them and asks for stronger actions. IO should be forbidden in the public system. They argue that CO is the weapon of a privileged majority against the powerless. Physicians in the public system cannot be CO; they are hired to carry out all the necessary practices. It is in the public system where permissible abortions should be performed as this is the only access poor women have to obtain safe and legal abortions. Hence, objectors should avoid providing public gynaecological services. Instead, they can work privately and exercise their $\mathrm{CO}$ in this sphere. Finally, temporary prohibition defenders contend that it is only when respect for these women and accessibility to their SS\&RR rights is achieved that $\mathrm{CO}$ will be accepted in the public system.

Note that the three candidate-positions argue for different policies that cannot be endorsed at the same time. The temporary prohibition proposal does not accept the other two. Universal accessibility to SS\&RR rights is non-existent in Argentina. Although the situation in some regions and cities is slightly better than what the temporary prohibition defender deals with, CO is not yet widely acceptable in the public system. Even the careful ruler proposal-which takes a middle-ground position-does not accept the silent referral or the temporary prohibition stances. In this regard, the careful ruler and the temporary prohibition position claim silent referral is too weak: merely proposing a quiet referral to another centre or another physician offering closed-door services. They call for an explicit message stressing the importance of SS\&RR rights. They also point out that it may be quite problematic to implement the silent referral proposal for urgent cases or for the morning after' pill ${ }^{\text {ix }}$ where hours count and the nearest hospital or physician may be remote (not to mention the waste of scarce resources for having to send an ambulance for emergency contraception). Nor is the temporary prohibition position feasible for the careful ruler. She will ask if it is possible to implement such public policy in a hostile context and if that policy is not unrealistic. Objectors may argue that they are martyrs of the system: they are targeted by an authoritarian rule. Will the temporary prohibition position be open-as the silent referral claims - to an even stronger reaction? Depicted as extreme and authoritarian, this position may be at risk of losing the little support defenders of women's rights have in such civil society.

Finally, advocates of the other two positions will not accept the careful ruler compromise. The temporary prohibition defender will deem it too mild, conceding too much to existing conditions. The silent referral will judge it unacceptable as it could risk the few advances they have gained with great effort. In addition, both will point out that setting all these rules can overburden the public system, asking for a registry with irksome and inconvenient periodic reviews. They will also question how they will manage and organise objectors and non-objectors (including the objectors' natural desire for promotions and for eligibility to become chiefs of the gynaecological wards, and so on).

Although the three positions claim that the priority is to provide services to women in need, they present strong differences regarding their implementation. Our mindful objector accepts their core arguments; however, she wonders whether

\footnotetext{
${ }^{\mathrm{ix}}$ Many objectors consider the 'morning after pill' abortive and do not
} make this kind of drug available. they are all acceptable and what she should do. Even if she recognises that these are matters for public policies, knowing which policy is correct will influence her decisions regarding her patient. Should she refer her patient to a colleague? And, what if she cannot find a non-objector? Should she object?

\section{THE NON-IDEAL APPROACH}

As we have already seen, if we consider the background conditions, the IT as it stands does not seem to fit. Choosing one of the above positions is no easy decision. Instead, we can regard each of the previous proposals as a NIT. Thus, we need an alternative analysis to consider NITs and the background situation.

Let us consider Rawls' distinction between NIT and IT that we outlined in the introduction. The first NIT is the partial compliance theory (PCT). PCT is prescribed for the case in which individuals do not fully comply. For example, it specifies what happens to an individual's obligations when others fail to do their fair share within some distributive scheme. Rawls also includes the theory of punishment and restitution and civil disobedience in the PCT.

The second branch of NIT is transitional theory (TT). TT prescribes for the cases in which background institutions are not just. It specifies obligations when individuals have to bring just institutions into existence (background institutions may be unjust or may not exist).

NITs are gradual. They are constructed step by step, aiming for the ideal. A related feature is that they should be reconsidered and amended as circumstances change. NIT policies are not written in stone. In this sense there is a dynamic component included in this way of analysing the situation. Finally they should be considered provisional or transitory, that is, when the situation and circumstances ameliorate NIT can be replaced or abandoned.

Examining our case again, we have already seen that there is partial compliance: almost no physician performs the service in the public sector. PCT will prescribe physicians' obligations when others fail to do their fair share. PCT applied to our case will focus on non-objector physicians and their obligations.

Liam Murphy thoroughly examined PCT. ${ }^{\mathbf{x}}$ Murphy assumes that the ideal requirements of justice are to maximise everyone's total well-being. Under circumstances of partial compliance, total well-being remains at a suboptimal level. However, if a given individual can relieve some of the shortfall by contributing still more, then utilitarianism will require even more of that agent. Murphy claims that this is not fair. ${ }^{11}$ xi If we consider this argument and apply it to the case at hand, there should not be an overimposition to non-objectors of what objectors do not do. A first strategy can be inferred: a system avoiding overburdening these physicians should be designed and implemented, for example, constructing a system of quotas or ways by which the system compensates the non-objector. Another possibility is implementing special centres where abortions and SS\&RR healthcare are handled appropriately without encumbering other physicians. Following this, referral policies should be handled with care in order not to overburden the few compliant physicians.

${ }^{\mathrm{x} I}$ will follow Sreenivasan's reconstruction. ${ }^{56}$

${ }^{x i}$ Murphy introduces a 'compliance condition' which holds (roughly) that the cost to an agent of complying with the requirements of beneficence should not be higher under partial compliance than they are under full compliance. We will not enter in the details here. However plausible, a debate arose and generated counter examples (see ref. 5, p.138). 
Could the objector also be deemed a civil disobedient? I believe the objector is not a civil disobedient, despite the similarities. Civil disobedience is a public, non-violent and conscientious breach of the law undertaken with the aim of bringing about changes in laws or policies. The civil disobedient is willing to accept punishment for actions taken. CO has different features. ${ }^{\text {xii }}$

Let us consider the second branch of NITs: TT. In the case at hand we are also faced with unjust institutions: institutions that do not provide what is legally allowed ${ }^{\text {xiii }}$ and harm the weakest. Thus, the TT will prescribe and specify the obligations individuals must fulfil to bring just institutions into existence. We do not have an analysis like the one Murphy provided in the case of PCT. Nonetheless, I argue that we can explore some new possibilities by considering TT in relation to IT.

TT works with a priority assumption, namely, that IT is prior to NIT and NIT proceeds by reference to the content of an IT. Rawls points this out:

NIT asks how this long-term goal might be achieved, or worked toward, usually in gradual steps. It looks for policies and courses of action that are morally permissible and politically possible as well as likely to be effective. So conceived NIT presupposes that IT is already on hand. For until the ideal is identified, at least in outline-and that is all we should expect-NIT lacks an objective, an aim, by reference to which its queries can be answered. ${ }^{\text {xiv }}$

If we follow Rawls' suggestion and consider the IT outline, we can infer other intermediate policies and design a NIT for CO. IT dictates the objective, and NIT indicates the route to that objective. As we saw in the introduction on the one hand, IT prescribes that permissible abortions should be provided; so, public hospitals should be carefully organised with protocols in order to avoid lengthy procedures, delays and so on. Other strategies can include adequate training for physicians; public campaigns can be implemented targeting the importance of this work, sensitising colleagues and the community to avoid stigmatising non-objectors.

On the other hand, IT prescribes accepting CO; so, truthful objectors should be accepted and abuses should be rejected. Public and transparent registries may help hinder abuses: objectors should renew their willingness to continue as $\mathrm{CO}$ or withdraw. Finally, IO if permitted at all has to be prevented from forcing non-objectors to behave as objectors out of fear or in order to maintain their jobs.

NIT requires that specific policies and courses of actions must be: R.1. Morally permissible; R.2. politically possible; R.3. likely to be effective. ${ }^{\mathrm{xv}}$ In addition to these requirements, Simmons infers another requirement-R.4. that the most grievous injustices are to be dealt with before less severe ones. ${ }^{\text {xvi }}$

The three proposals our mindful physician considered in the previous section can now be evaluated following this NIT framework. If we observe the priority assumption as well as the four

\footnotetext{
xii Typically, conscientious objectors do not aim to communicate their action to the government or society with the goal of bringing about a change. It is a personal position: because of their beliefs they do not want to perform an action. Nor are they willing to accept punishment. Also, while civil disobedience is invariably illegal, $\mathrm{CO}$ is sometimes legal.

xiiiArgentina has a public system that provides access to healthcare services to all persons. More than $99 \%$ of pregnancies are institutionalised. So not providing permissible abortions in the public system involves a bias, an abusive and unfair action.

${ }^{\text {xiv }}$ See ref. 4, pp.89-90.

${ }^{\mathrm{xv}}$ Ibidem.

${ }^{\mathrm{xv}}$ See ref. 3, pp.18-19.
}

requirements, we can select the one that better leads to the IT. The temporary prohibition position fails the true objector. It only considers abusive positions. It does not take profound and deeply held religious convictions seriously; but most importantly, it does not seem to be politically possible with such conservative groups in the region (R.2) and thus not likely to be effective (R.3).

The silent referral proposal does not accept the system of public registries or quotas as there are no constraints on objectors. It would appear to be more protective of objectors than women's needs. This goes against R.4 whereby women's lack of access to permissible abortions is the most grievous injustice as they may die from unsafe abortions. They are the worst off. Silent referral also accepts IO which does not seem to be morally permissible (R.1): because of the abuse it involves, and because it is authoritarian and acts against the autonomy of subordinates. And finally, even if it would appear to be politically acceptable as it looks quite pragmatic (R.2), it is not clearly effective (R.3) because of delays, waste of resources, and so on.

The careful ruler position instead, may be the best fitted NIT. It accepts that there might be true objectors, gives priority to the adequate provision of the service, asks for measures to hinder abuses (requires a public registry, quotas, and rejects IO). It clearly adopts most of the strategies outlined above and can accept others in this vein.

Thus, NIT helps conceptualise problems in a context of noncompliance and extreme scarcity better and more realistically. Using an IT and NIT distinction and considering their relationship may help justify medium-term strategies, and select the best NIT. As it is provisional, when performing permissible abortions in public hospitals is accepted and well implemented, without massive non-compliance, the rules settled by PCT and TT will be able to end. At this point we can switch to the IT.

This is just a first step. I take Rawls and his interpreters as a guide, but other authors or theories can be explored given the amount of work to be done. Yet, it seems clear that NIT in circumstances of excessive scarcity, non-compliance and injustice is what we, as bioethicists, should consider seriously.

Even if policy design differs from individual decisions, knowing the correct policy may help indicate what we should do. I do not claim there is a direct impact but only that this knowledge may be helpful for personal deliberation in indeterminate or non-ideal situations and that doctors should seriously consider this kind of theoretical tool. Thus, if our mindful objector examines the framework NIT provides, she will have a better picture of the situation and might recognise that in such non-ideal circumstances she should not object. However, as performing abortions may still be too difficult, she might decide to work in a related area where abortions are not performed or choose to go into the private system where she can object. If she still wants to work in the public system or in that service, she may decide to build a just institution (ask for proper registries, quotas, and an adequate and just referral system). With respect to preservation of her patient's health and life, she may immediately refer her to another colleague in the institution or seek another institution where the abortion can be carried out properly. But if she cannot find a colleague, she should, however reluctantly, do it herself.

Ultimately, we are left with a bittersweet taste in our mouths. In these non-ideal situations we have to acknowledge that no perfect solutions exist. Solutions, like the circumstances we experience, are imperfect... though they can aim for the ideal.

Acknowledgements I would like to thank Joe Millum, Ruth Macklin, Marcelo Alegre, Eduardo Rivera López and Ignacio Mastroleo for their comments on previous versions.

Luna F. J Med Ethics 2015;41:129-133. doi:10.1136/medethics-2014-102295 
Competing interests None.

Provenance and peer review Commissioned; internally peer reviewed.

\section{REFERENCES}

1 Luna F. Poverty and inequalities: challenges for the IAB. Bioethics 2005;19(5-6): 451-60.

2 Millum J, Emanuel E. Global justice and bioethics. Oxford: Oxford University Press, 2012.

3 Simmons J. Ideal and nonideal theory. Philos Public Aff 2010;38(1):5-36.

4 Rawls J. The law of peoples. Cambridge, MA: Harvard University Press, 1999: Section 2, 39, 69

5 Sreenivasan G. Nonideal theory: a taxonomy with illustration. In: Millum J, Emanuel E, eds. Global justice and bioethics. Oxford: Oxford University Press, 2012:153-77.
6 Murphy L. Moral demand in nonideal theory. New York: Oxford University Press, 2000.

7 Feinberg J. Duties and obligations in the non-ideal world. J Philos 1973;70: 263-75.

8 Goodin R. The bioethics of second-best. In: Millum J, Emanuel E, eds. Global justice and bioethics. Oxford: Oxford University Press, 2012:153-77.

9 Alegre M. Objeción de conciencia y salud sexual y reproductiva. despenalización. org.ar 2009; 10. http://www.despenalizacion.org.ar/pdf/Hojas Informativas/10 Alegre.pdf (accessed 20 Aug 2014).

10 Deza S, Iriarte A, Alvarez M. Jaque a la reina. Buenos Aires: Cienflores, 2014.

11 Arneson R. Moral limits on the demands of beneficence? In: Chatterjee D, ed. The ethics of assistance: morality and the distant needy. New York: University Press, 2004:33-58 